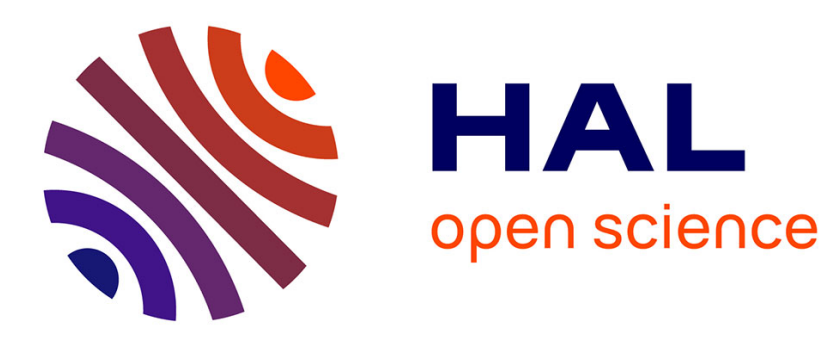

\title{
Detailed optical characterization of the deep cr level in gaas
}

\author{
A. Nouailhat, F. Litty, S. Loualiche, P. Leyral, G. Guillot
}

\section{To cite this version:}

A. Nouailhat, F. Litty, S. Loualiche, P. Leyral, G. Guillot. Detailed optical characterization of the deep cr level in gaas. Journal de Physique, 1982, 43 (5), pp.815-825. 10.1051/jphys:01982004305081500 . jpa-00209456

\section{HAL Id: jpa-00209456 https://hal.science/jpa-00209456}

Submitted on 1 Jan 1982

HAL is a multi-disciplinary open access archive for the deposit and dissemination of scientific research documents, whether they are published or not. The documents may come from teaching and research institutions in France or abroad, or from public or private research centers.
L'archive ouverte pluridisciplinaire HAL, est destinée au dépôt et à la diffusion de documents scientifiques de niveau recherche, publiés ou non, émanant des établissements d'enseignement et de recherche français ou étrangers, des laboratoires publics ou privés. 
Classification

Physics Abstracts

$71.55-78.50-78.55$

\title{
Detailed optical characterization of the deep $\mathrm{Cr}$ level in GaAs
}

\author{
A. Nouailhat, F. Litty, S. Loualiche, P. Leyral and G. Guillot \\ Laboratoire de Physique de la Matière (*), Institut National des Sciences Appliquées de Lyon, \\ 20, avenue Albert Einstein, 69621 Villeurbanne Cedex, France
}

(Reçu le 27 octobre 1981, révisé le 12 janvier 1982, accepté le 27 janvier 1982)

\begin{abstract}
Résumé. - Les caractéristiques optiques du niveau profond "HL1" lié à la présence du chrome dans GaAs ont été étudiées par différentes méthodes pour donner une description précise du centre. Les sections efficaces d'ionisation optique $\sigma_{\mathrm{n}}^{\circ}(h v)$ et $\sigma_{\mathrm{p}}^{\circ}(h v)$ ont été mesurées par spectroscopie capacitive optique (Deep Level Optical Spectroscopy - DLOS) sur GaAs LPE de type $n$ et $\mathrm{p}$ dopé au chrome. Ces résultats permettent de déterminer l'état de charge du chrome dans un matériau massif par mesure d'absorption optique. L'origine des émissions à 0,57 et $0,62 \mathrm{eV}$ liées au chrome est clairement démontrée par comparaison de leurs spectres d'excitation avec $\sigma_{\mathrm{n}}^{\circ}$ et $\sigma_{\mathrm{p}}^{\circ}$. L'ensemble des résultats donne une description cohérente des propriétés thermiques et optiques du niveau correspondant aux deux états $\mathrm{Cr}^{+2}-\mathrm{Cr}^{+3}$.
\end{abstract}

\begin{abstract}
The deep level optical spectroscopy by the so called DLOS technique gives the spectral shape of both $\sigma_{n}^{\circ}(h v)$ and $\sigma_{p}^{o}(h v)$, the optical cross sections for the transitions between a deep level and the conduction and valence bands, in a very sensitive and selective way. We have applied this technique to the optical study of the HL1 trap related to chromium in GaAs, in very pure LPE layers of $n$ and $p$ type doped with chromium. We can therefore determine what kind of charge states of chromium we are dealing with by comparing $\sigma_{\mathrm{n}}^{\circ}$ and $\sigma_{\mathrm{p}}^{\circ}$ with the optical absorption spectra in bulk materials. Moreover, comparisons between the excitation spectra of luminescence and the photoionization cross section $\sigma_{\mathrm{n}}^{\mathrm{o}}$ and $\sigma_{\mathrm{p}}^{\mathrm{o}}$ have given unambiguous interpretation of the origin of the two luminescence bands at 0.57 and $0.62 \mathrm{eV}$ found by YAG laser excitation in bulk $\mathrm{Cr}$ doped GaAs depending on the Fermi level position. They are interpreted as the radiative transitions between the $\left(\mathrm{Cr}^{3+}-\mathrm{Cr}^{2+}\right)$ centre and the bands. In this way, we give a coherent description of the thermal and optical properties of the single deep acceptor level corresponding to the $\mathrm{Cr}^{3+}$ or $\mathrm{Cr}^{2+}$ states according to its electronic filling.
\end{abstract}

1. Introduction. - Chromium doping of III-V semiconductors such as GaAs, GaP and InP is known to produce semi-insulating materials by formation of deep levels in the gap which compensate the net residual shallow donors. This type of material, specifically for $\mathrm{GaAs}$ : $\mathrm{Cr}$ has a great technological importance as substrates for device fabrication [1]. Consequently, the physical nature and the properties of the $\mathrm{Cr}$ centre which control the electrical properties of the material has been the subject of several studies and numerous techniques have been applied : optical spectroscopic measurements like luminescence [2-6], absorption [7-11], ESR studies [12-17], electro-optical measurements such as Deep Level Transient Spectroscopy (DLTS) and photocapacity [18-24], Optical Transient Current Spectroscopy (OTCS) [25-27], photoconductivity and photo-Hall methods [28-31].

It is now rather well established that the deep level

(*) Equipe de recherche associée au C.N.R.S. related to chromium which plays the main role in the compensation mechanism is a chromium atom on a $\mathrm{Ga}$ site. Thus there could exist three charge states : neutral $\mathrm{Cr}^{3+}\left(\mathrm{d}^{3}\right)$, one singly negatively charged $\mathrm{Cr}^{2+}\left(\mathrm{d}^{4}\right)$ and doubly negatively charged $\mathrm{Cr}^{+}\left(\mathrm{d}^{5}\right)$ by capturing one or two electrons respectively. Up to very recently, the existence of two deep levels associated with the three charge states of $\mathrm{Cr}$ has been controversial. Through Hall and chemical analysis data, Brozel et al. [32] postulated that chromium can act as a double acceptor state confirming thus the possibility of three charge state as first argued by ESR results [12]. Nevertheless in spite of some electrooptical results on space charge barriers which relate two acceptor states to chromium in the gap [21, 22], it has been clearly demonstrated by Clerjaud et al. [10] using ESR and hydrostatic pressure measurements that the double acceptor $\mathrm{Cr}^{+}$energy level is above the $\mathrm{GaAs}$ conduction band and this conclusion has been reinforced by the recent reinterpretation of the first assigned $\mathrm{Cr}^{+1}$ signal as due to $\mathrm{Cr}^{4+}[17,33]$. 
The aim of this paper is double :

i) firstly, to determine experimentally the spectral distributions of the optical cross sections $\sigma_{n}^{o}(h v)$ and $\sigma_{\mathrm{p}}^{\mathrm{o}}(h v)$ for the transitions between HL1 and the conduction and valence bands respectively;

ii) secondly, to confirm by optical measurements that there is a unique deep acceptor state (labelled HL1) the thermal parameters of which have been measured very precisely by Martin et al. [20].

This first point is very important for many reasons, theoretical as well as practical. From a theoretical point of view, the photoionization cross sections can provide unique information concerning the ionization energies of the levels, the electron-phonon interactions, the coupling of deep levels to the bands.

From a practical point of view, optical absorption measurements appear to be the most reliable technique (because it is easy and non destructive) to obtain the concentration $N_{\mathrm{T}}$ of deep levels in semi-insulating materials. In fact, the optical absorption coefficient $\alpha$ resulting from all the transitions associated to the different level $i$ is [34] :

$$
\alpha=\sum_{i} A_{i} N_{\mathrm{T} i}\left[\sigma_{\mathrm{n} i}^{\mathrm{o}} f+\sigma_{\mathrm{p} i}^{\mathrm{o}}(1-f)\right]
$$

where $A$ : constant

$N_{\mathrm{T} i}$ : concentration of a given deep level $i$

$f$ : Fermi function.

In $\mathrm{Cr}$ doped or undoped semi-insulating GaAs, it has been shown that practically only two deep levels HL1 and the deep donor EL2 are responsible for the absorption spectra observed and that optical absorption measurements can give the concentration of $\mathrm{Cr}$ (either in $\mathrm{Cr}^{2+}$ or $\mathrm{Cr}^{3+}$ state) and EL2 after accurate calibration [34]. For the use of (1) we need the precise determination in a large range of energy of $\sigma_{\mathrm{n}}^{\mathrm{o}}$ and $\sigma_{\mathrm{p}}^{\mathrm{o}}$.

For the measurements of $\sigma_{n}^{o}$ and $\sigma_{p}^{o}$ of HL1, we have used a very new attractive experimental method called deep level optical spectroscopy (DLOS), first reported by Bois and Chantre [35, 36, 37]. DLOS is a new transient photocapacitance technique allowing a true deep level optical spectroscopy by direct, unambiguous and independent measurements of both $\sigma_{n}^{\circ}$ and $\sigma_{\mathrm{p}}^{\mathrm{o}}$ cross sections over a large photon energy range with a very good sensitivity and selectivity when several deep levels are present in a given material, which cannot be done by classical photoconductivity or photocapacitance measurements. Moreover, DLOS spectra can be quite easily associated to deep levels identified by DLTS through their thermal signatures.

Furthermore, the knowledge of $\sigma_{n}^{o}$ and $\sigma_{p}^{o}$ can help to clarify many experimental data such as photoluminescence results [38] or photoinduced ESR signals $[15,39]$. One of our aims was also to measure the excitation spectra of two luminescence bands peaking at $0.57 \mathrm{eV}$ and $0.62 \mathrm{eV}$ found in $\mathrm{GaAs}: \mathrm{Cr}$ by YAG laser excitation and which have tentatively attributed to the transition between the $\left(\mathrm{Cr}^{3+}-\mathrm{Cr}^{2+}\right)$ level and the valence band and conduction band respectively [38] and to correlate them with the shape of $\sigma_{\mathrm{n}}^{\mathrm{o}}$ and $\sigma_{\mathrm{p}}^{\mathrm{o}}$ of the same centre. Some preliminary results have already been reported [40].

This paper will start with a rapid description of the experimental techniques used in section 2 . In section 3 , the experimental results on the photoionization cross sections, the photoluminescence experiments (emission and excitation spectra) will be presented. The last section will be devoted to a discussion reviewing all the transitions which can be associated with the $\left(\mathrm{Cr}^{3}-\mathrm{Cr}^{2+}\right)$ level in $\mathrm{GaAs}$ and comparison with optical absorption results on some $\mathrm{GaAs}: \mathrm{Cr}$ of different types.

2. Experimental techniques. -2.1 PhotocAPACITANCE EXPERIMENTS. - The experimental set-up for the Deep Level Optical Spectroscopy (DLOS) measurements has already been described [35]. The ionization cross sections of the deep levels can be selectively determined in the energetic range $0.4 \mathrm{eV}-E_{\mathrm{G}}$, with $E_{\mathrm{G}}$ : band to band transition energy at the temperature of the measurement. In general, we use as photoexcitation source a $150 \mathrm{~W}$ tungsten lamp followed by the premonochromator of a Perkin-Elmer $112 \mathrm{G}$ provided with a $\mathrm{LiF}$ prism. In the range $0.75 \mathrm{eV}-E_{\mathrm{G}}$, we also use as excitation source a $50 \mathrm{~W}$ tungsten lamp followed by a Bausch and Lomb high intensity monochromator (grating of 675 lines $/ \mathrm{mm}$ blazed at $1 \mu \mathrm{m})$. In the last case, the second order light is eliminated by appropriate filters. The flux was previously measured and the flux correction is directly included in the program of data processing in the HP 9821 computer monitoring the experimental sequences (voltage of sample polarization, wavelength of the illumination, temperature, data acquisition...).

DLOS experiments are performed using $\mathrm{Cr}$ doped layers grown at Cornell University by liquid phase epitaxy : a $\mathrm{p}^{+} \mathrm{pn}^{+}$junction for the $\sigma_{\mathrm{p}}^{\mathrm{o}}$ measurement and a $n$ type layer for the $\sigma_{n}^{o}$ measurement on Schottky barrier. A detailed study of the electrical characterization of the deep $\mathrm{Cr}$ level in these materials is given in [20] and their electrical parameters in table $I$.

2.2 PhotoluminesCENCE EXPERIMENTS. - The experimental set-up for the photoluminescence (PL) measurements has already been described [40]. The detection is made with a Bausch and Lomb high intensity monochromator (grating 337.5 lines/mm blazed at $2 \mu \mathrm{m}$ ) followed by a $\mathrm{PbS}$ cell at $77 \mathrm{~K}$, the excitation with a YAG laser $(1 \mathrm{~W}$ at $1.06 \mu \mathrm{m})$ and the sample temperature can be fixed between $4 \mathrm{~K}$ and $300 \mathrm{~K}$.

In the case of the excitation spectra of luminescence (ESL), the excitation source is a $50 \mathrm{~W}$ tungsten lamp followed by a Bausch and Lomb high intensity monochromator (grating of 675 lines $/ \mathrm{mm}$ blazed at $1 \mu \mathrm{m}$ ) and the emission bands of interest are selected by appropriate filters. 
Table I. - Parameters of undoped and $\mathrm{Cr}$ doped GaAs crystals studied in photoluminescence and DLOS.

\begin{tabular}{|c|c|c|c|c|c|}
\hline Samples & Type & $\begin{array}{c}\text { Carrier } \\
\text { concentration }\end{array}$ & $\begin{array}{l}\text { Weight ratio of } \mathrm{Cr} / \mathrm{GaAs} \\
\text { in the melt }\end{array}$ & $\begin{array}{l}\mathrm{Ga}_{2} \mathrm{O}_{3} / \mathrm{GaAs} \\
\text { (in weight) }\end{array}$ & $\begin{array}{c}\mathrm{Si} / \mathrm{GaAs} \\
\text { (in weight) }\end{array}$ \\
\hline- & - & - & - & - & - \\
\hline RT 221 & n Bridgman & $10^{16} / \mathrm{cm}^{3}$ & $6 \times 10^{-5}$ & 0 & \\
\hline RT $427 \mathrm{Q}$ & $\mathrm{n}$ Bridgman & $\sim 3 \times 10^{16} / \mathrm{cm}^{3}$ & $2.4 \times 10^{-4}$ & 0 & $0.05 \times 10^{-4}$ \\
\hline Ga $735(3)$ & n Bridgman & $10^{16} / \mathrm{cm}^{3}$ & $10^{-3}$ & 0 & $0.5 \times 10^{-5}$ \\
\hline RT 193 & SI Bridgman & & $5.6 \times 10^{-4}$ & & \\
\hline RT 356 & SI Bridgman & & & & \\
\hline RT 399 & SI Bridgman & & & & \\
\hline RT $437 \mathrm{Q}$ & SI Bridgman & & & & \\
\hline RT 512 & SI Bridgman & & $2 \times 10^{-4}$ & $0.1 \times 10^{-4}$ & 0 \\
\hline RT 616 Q & SI Bridgman & & $2 \times 10^{-4}$ & & \\
\hline CL 2T (75) & SI Czochralski & & $5.6 \times 10^{-4}$ & 0 & \\
\hline CL $45 \mathrm{~T}(104)$ & SI Czochralski & & $2.3 \times 10^{-4}$ & 0 & \\
\hline CL 57 T (2) & p Czochralski & & & & \\
\hline CN 7-15-L & p Czochralski & & $\{\mathrm{Cr}\}=1-2 \times 10^{16} \mathrm{~cm}^{-3}$ & & \\
\hline Ga $781(9)$ & p Bridgman & $\mathrm{p}=10^{17} \mathrm{~cm}^{-3}$ & $10^{16} \mathrm{~cm}^{-3}<\{\mathrm{Cr}\}<10^{17} \mathrm{~cm}^{-3}$ & & \\
\hline LPE 2828 & $\mathrm{n}^{+} \mathrm{pp}^{+}$structure & $\mathrm{p}=9 \times 10^{15} \mathrm{~cm}^{-3}$ & $\{\mathrm{Cr}\}=5 \times 10^{14} \mathrm{~cm}^{-3}$ & & \\
\hline LPE $2820 \mathrm{~B}$ & $\mathrm{n}$ layer $/ \mathrm{n}^{+}$ & $\mathrm{n}=6 \times 10^{14} \mathrm{~cm}^{-3}$ & $\{\mathrm{Cr}\}=4 \times 10^{14} \mathrm{~cm}^{-3}$ & & \\
\hline
\end{tabular}

All the emission and excitation spectra are corrected for filters, lens and grating transmission, $\mathrm{PbS}$ cell spectral detectivity and for the spectral distribution of the exciting radiation (for the ESL).

Most of the samples come from RTC : all of them were Bridgman materials doped with chromium during the growth process. We have also studied some Czochralski grown material doped with chromium during the growth at LEP and NRL. The samples are all chromium doped and are of $n, p$ and semiinsulating type (table I).

3. Experimental results and theoretical treatments. - 3.1 Photolonization CROSS SECTIONS $\sigma_{\mathrm{p}}^{\circ}$ AND $\sigma_{\mathrm{n}}^{\circ}$ OF $\mathrm{HL}_{1}$ (HIGH TEMPERATURE MEASUREMENTS). 3.1.1 Measurement procedure. - a) $\sigma_{\mathrm{n}}^{\mathrm{o}}$ - - We have used the electrical DLOS method [35] on Schottky diode $\mathrm{Au} \mathrm{n} / \mathrm{n}^{+}$(LPE $2820 \mathrm{~B}$ ). The initial charge state of the deep levels in the diode depletion layer is determined by a short pulse putting the diode in forward bias, filling the traps with majority carriers. The illumination with a monochromatic photon flux leads to a photocapacitance signal, when the ionization of centres occurs. For one trap, the derivative of the capacitance transient at the beginning of the illumination is proportional to $\frac{1}{h v} \phi(h v) \sigma_{\mathrm{n}}^{\mathrm{o}}$ with $\frac{1}{h v} \phi(h v)$ : density of the photons with frequency $v$ into the depletion layer in the measurement conditions. For the case of the chromium, we measure the ionization cross section of the transition $\mathrm{Cr}^{+2} \stackrel{h v}{\longrightarrow} \mathrm{Cr}^{+3}+\mathrm{e}_{\mathrm{BC}}^{-} \cdot \sigma_{\mathrm{n}}^{\mathrm{o}}$ is shown in figure 1.

The optical absorption of an $\mathrm{n}$ type GaAs doped with chromium (after [7]) is also given on the figure. The agreement with $\sigma_{\mathrm{n}}^{\mathrm{o}}$ is very good taking into account the difference of the materials used. In the case of the optical absorption, a significant increase at energy greater than $1 \mathrm{eV}$ is due to other deep levels.

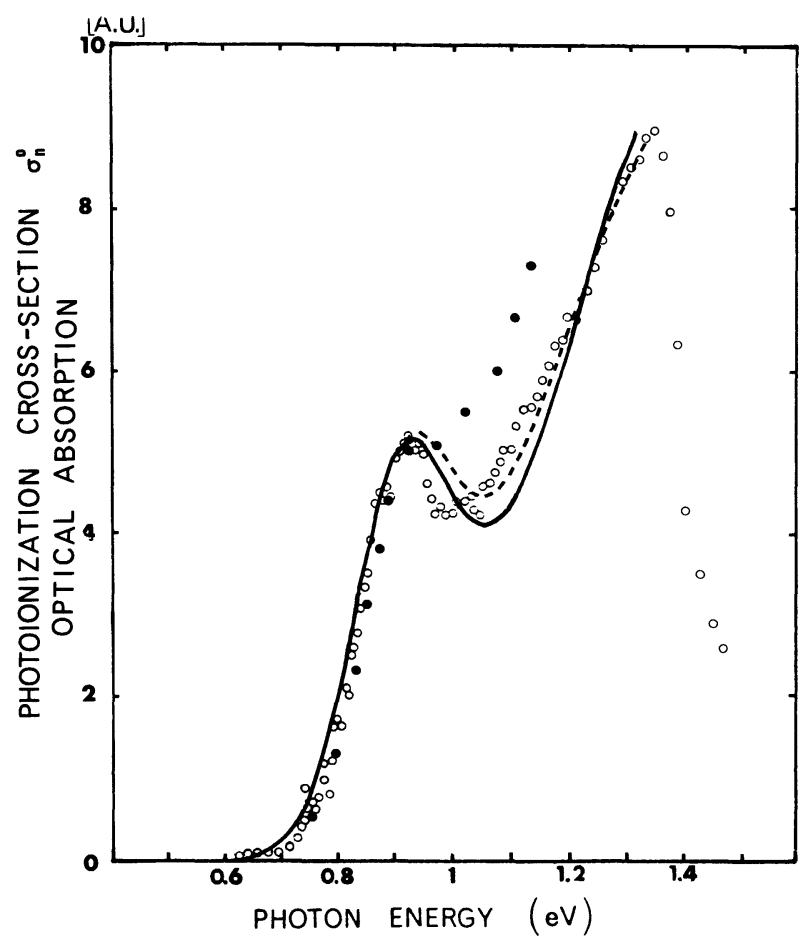

Fig. 1. - Photoionization cross section $\sigma_{n}^{\circ}$ of HL1 measured at $300 \mathrm{~K}$ on $\mathrm{n}$ type LPE GaAs doped with chromium. O०O : experiment ; _ _ : theoretical fit I ; ---- : theoretical fit II (see text and table II); 0 : optical absorption spectra $(300 \mathrm{~K})$ of a $\mathrm{n}$ type $\mathrm{Cr}$ doped GaAs sample [7].

b) $\sigma_{\mathrm{p}}^{\mathrm{o}}-b .1$. The previous method, called electrical DLOS, was used with the $n^{+} p / p^{+}$junction (LPE 2828). In this case, the filling pulse amplitude of majority carriers (holes) must not exceed the bias value. A more important amplitude should also inject minority carriers in the $p$ region. With this condition, all the chromiums are in the initial empty charge state $\mathrm{Cr}^{3+}$. The derivative of the capacitance transient at the 


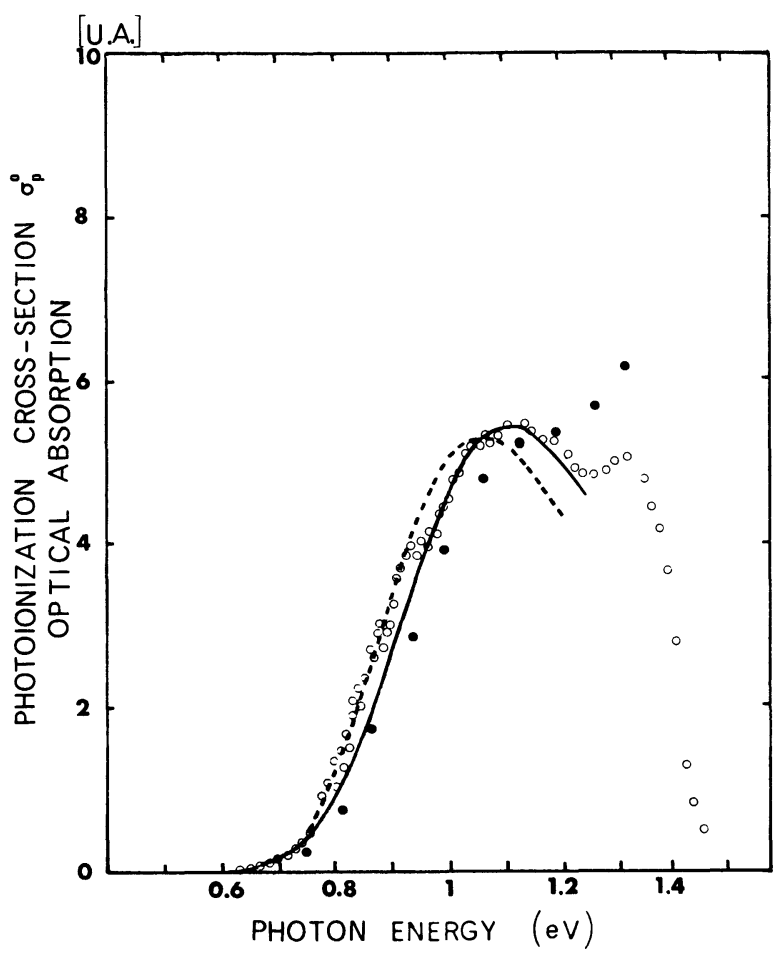

Fig. 2. - Photoionization cross section $\sigma_{\mathrm{p}}^{\mathrm{o}}$ of HL1 measured at $320 \mathrm{~K}$ on $\mathrm{p}$ type LPE GaAs doped with chromium. OOO : experiment; - $:$ theoretical fit $\mathrm{I} ;$--- : theoretical fit II (see text and table III); $\bullet$ : optical absorption spectra $(300 \mathrm{~K}$ ), of a semi-insulating or $\mathrm{Cr}$ doped $\mathrm{GaAs}$ sample with large ratio $\mathrm{Cr}^{+3} / \mathrm{Cr}^{+2}$ [42]

beginning under photon flux is then proportional to $\frac{1}{h v} \phi(h v) \sigma_{\mathrm{p}}^{\mathrm{o}}$. This is absolutely true, as in the previous case, only if on the one hand the thermal emission rate is negligible in comparison with the optical one, on the other hand we have only the optical response of the HL1 trap. In this type of material, the presence of the centres HL2, HL5 and HL18 [20] do not permit the measure of $\sigma_{\mathrm{p}}^{\mathrm{o}}$ at different temperatures and $\sigma_{\mathrm{p}}^{\mathrm{o}}$ (HL1) was determined at $320 \mathrm{~K}$, figure 2 .

In the experimental conditions of the DLOS, at lower temperature the response of HL2 appears and, at higher temperature, the thermal response of HL1 makes the optical response measurement impossible.

$b .2$. It is possible to measure $\sigma_{\mathrm{p}}^{\mathrm{o}}$ in the $\mathrm{n}$ typematerial (with Schottky diodes) using the optical DLOS procedure [35]. Unfortunately, in the case of HL1 centre, the observation of $\sigma_{\mathrm{p}}^{\mathrm{o}}$ and $\sigma_{\mathrm{n}}^{\mathrm{o}}$ shows that it is not possible to find a determined optical frequency to empty the traps completely. Using, after the optical emptying pulse, the same procedure to measure the kinetic under illumination as in electrical DLOS, we have a response which is a linear combination of $\sigma_{\mathrm{p}}^{\mathbf{o}}$ and $\sigma_{\mathrm{n}}^{\mathrm{o}}$. The knowledge of $\sigma_{\mathrm{n}}^{\mathrm{o}}$ permits mathematically to calculate $\sigma_{\mathrm{p}}^{\mathrm{o}}$. This procedure, previously used by Chantre [41], gives a result very close to the one obtained by electrical DLOS on the $n^{+} p / p^{+}$junction. However, the accuracy is not sufficient for a fine study of $\sigma_{\mathrm{n}}^{\mathrm{o}}$ with temperature. It simply appears that $\sigma_{\mathrm{p}}^{\mathrm{o}}$ varies very little with temperature, this is true to the theoretical results.

The optical absorption spectrum of a $\mathrm{Cr}$ doped S.I. GaAs is given for comparison [42]. The fact that the materials are quite different in the two experiments do not permit a very precise comparison because : (i) we can not compare the two scales without a point of normalization, as for $\mathrm{n} \mathrm{Cr-GaAs}$ at $0.9 \mathrm{eV}$; (ii) at high concentration of chromium, change in the absorption spectra occurs above $1 \mathrm{eV}$ [11]. Nevertheless, it appears that the two onsets are similar and we can easily fit DLOS and OA data in the range $0.6-1 \mathrm{eV}$, proving that the chromium in this S.I. material is in the large majority in the state $\mathrm{Cr}^{+3}$.

3.1.2 Theoretical treatment. - We use the theoretical model established in our laboratory by Chantre et al. [35] to fit the photoionization spectra. This model was developed in the framework of a strong coupling between the electron and the lattice. For the transitions between the centre and the bands, we take into account a single phonon mode $\hbar \omega$ linearly coupled to the electronic level. The numerical values of the constants used are deduced from the band structure $E(k)$ of GaAs approximated by parabola at the point $\Gamma, \mathrm{L}, \mathrm{X}$ [43]. The fit parameters are : the Franck Condon parameter $d_{\mathrm{FC}}$, the phonon energy $\hbar \omega$, the optical ionization thresholds $E^{\mathrm{o}}$ for the transitions $\mathrm{VB} \rightarrow$ centre and centre $\rightarrow$ CB. The adjustable parameters are : the different transition weights towards the $\Gamma, \mathrm{L}, \mathrm{X}$ bands, the parameter $\alpha^{-1}$ giving the information on the wave function extension of the bound electron. In the mathematical formulation of $\sigma_{n}^{o}$ and $\sigma_{p}^{o}$, we can consider the electronic transitions allowed or not, and the potential Coulomb as a Dirac one. Some of these parameters $\left(d_{\mathrm{FC}}, \hbar \omega\right)$ can be compared with those obtained by experimental results given by other methods like DLTS studies of phonon assisted tunnel emission of electrons [44, 45], luminescence [38] and optical absorption [10, 42].

We take into account published data concerning the structure of the centre namely :

(i) for $\sigma_{\mathrm{n}}^{\mathrm{o}}$ the model includes the internal transition of $\mathrm{Cr}^{+2}$ corresponding to the transition ${ }^{5} \mathrm{~B}_{2}\left({ }^{5} \mathrm{~T}_{2}\right) \rightarrow{ }^{5} \mathrm{~A}_{1}\left({ }^{5} \mathrm{E}\right)$ : the crystal field splits the ${ }^{5} \mathrm{D}\left(\mathrm{Cr}^{+2}\right)$ level in two levels of symmetry ${ }^{5} \mathrm{~T}_{2}$ and ${ }^{5} \mathrm{E}$. This electronic level being degenerate, the coupling with the lattice leads to a Jahn-Teller effect causing a splitting ${ }^{5} \mathrm{~T}_{2} \rightarrow{ }^{5} \mathrm{~B}_{2},{ }^{5} \mathrm{E}$ and ${ }^{5} \mathrm{E} \rightarrow{ }^{5} \mathrm{~A}_{1},{ }^{5} \mathrm{~B}_{1}$. The internal transition leads to a gaussian band of moments $E_{i}, \sigma_{i}$ well known by absorption measurements [7, 8]. It is detectable by DLOS also because the state ${ }^{5} \mathrm{~A}_{1}$ is in resonance with the conduction band and the ionization occurs ;

(ii) for $\sigma_{\mathrm{p}}^{\mathrm{o}}$, we must take into account the Jahn-Teller effect of the chromium in the state $\mathrm{Cr}^{+3}$ causing a structure of the transition of an electron of the valence band to the $\mathrm{Cr}^{+3}$. This was discussed by Martinez et 


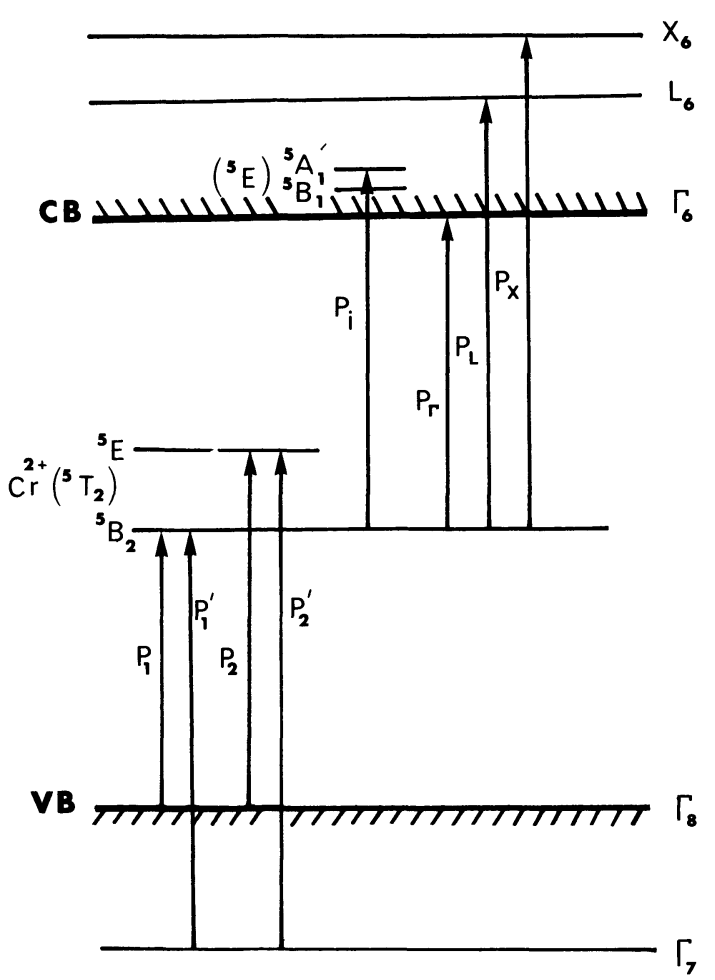

Fig. 3. - Scheme of the energy levels of the $\left(\mathrm{Cr}^{3+}-\mathrm{Cr}^{2+}\right)$ ion in GaAs involved in the fits of $\sigma_{\mathrm{p}}^{\mathrm{o}}$ and $\sigma_{\mathrm{n}}^{\mathrm{o}}(P=$ weight of a transition).

al. [9]. For this transition, the $\mathrm{Cr}$ is in the symmetry state of the $\mathrm{Cr}^{+3}$. The fundamental level ${ }^{5} \mathrm{~T}_{2}$ is split. Moreover the spin-orbit interaction leads to a splitting of the valence band, the value of which for $\Gamma$ being about $0.35 \mathrm{eV}$ in GaAs [46]. These different transitions and the symbols used are shown in figure 3 .

a) $\sigma_{\mathrm{n}}^{\circ}(300 \mathrm{~K})$. - Two theoretical fits of $\sigma_{\mathrm{n}}^{\mathrm{o}}$ are given in figure 1 which essentially rely on two different values of $d_{\mathrm{FC}}$ equal to $200 \mathrm{meV}$ after [45] or to $170 \mathrm{meV}$ after [42]. The optical ionization energy being then $E_{\Gamma}^{\mathrm{o}}=E_{\mathrm{C}}-E_{\mathrm{T}}+d_{\mathrm{FC}}$ with $E_{\mathrm{C}}-E_{\mathrm{T}}$ equal to the thermal activation energy value already determined of $0.7 \mathrm{eV}$ (at $350 \mathrm{~K}$ ) [20]. The values of energetic interval $E_{\mathrm{L}}^{\mathrm{o}}-E_{\Gamma}^{\mathrm{o}}, E_{\mathrm{X}}^{\mathrm{o}}-E_{\Gamma}^{\mathrm{o}}$ are given by [43]. Furthermore, the weighting factors are adjusted in order to fit the high energy part of $\sigma_{\mathrm{n}}^{\circ}$.

Table II. - Numerical data used for the fits of $\sigma_{\mathbf{n}}^{\circ}$ $(300 \mathrm{~K})$ in figure 1.

\begin{tabular}{|c|c|c|c|c|c|c|c|c|}
\hline Fit & $\begin{array}{c}E_{i}^{\mathbf{o}} \\
(\mathrm{eV})\end{array}$ & $\begin{array}{c}\sigma_{i} \\
(\mathrm{eV})\end{array}$ & \multicolumn{3}{|c|}{$\begin{array}{c}\text { Norme } / \text { transition } \rightarrow \Gamma \\
\qquad P_{i} / P_{\Gamma}\end{array}$} & & & \\
\hline \multirow{3}{*}{$\begin{array}{r}\text { I } \\
\text { II }\end{array}$} & 0.91 & 0.083 & \multirow{2}{*}{\multicolumn{3}{|c|}{$\begin{array}{l}0.02 \\
0.016\end{array}$}} & & & \\
\hline & 0.01 & & & & & & & \\
\hline & $\begin{array}{c}E_{\Gamma}^{\mathrm{o}} \\
(\mathrm{eV})\end{array}$ & $\begin{array}{l}d_{\mathrm{FC}} \\
(\mathrm{eV})\end{array}$ & $\begin{array}{l}\Delta E_{\Gamma \mathrm{L}}^{\mathrm{o}} \\
(\mathrm{eV})\end{array}$ & $\begin{array}{c}\Delta E_{\Gamma \mathrm{x}}^{\mathrm{o}} \\
(\mathrm{eV})\end{array}$ & $P_{\Gamma}$ & $P_{\mathrm{L}} / P_{\Gamma}$ & $P_{\mathrm{X}} / P_{\Gamma}$ & $\begin{array}{l}\alpha^{-1} \\
(\AA)\end{array}$ \\
\hline I & 0.9 & 0.2 & 0.29 & 0.48 & 1 & 0.12 & 0.05 & 5 \\
\hline II & 0.87 & 0.17 & 0.29 & 0.48 & 1 & 0.102 & 0.045 & 5 \\
\hline
\end{tabular}

Table III. - Numerical data used for the fits of $\sigma_{\mathrm{p}}^{\mathrm{o}}$ $(320 \mathrm{~K})$ in figure 2.

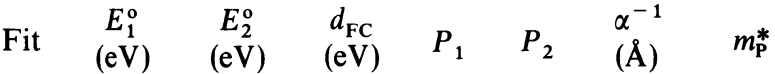

$$
\begin{aligned}
& \begin{array}{cccccccc}
- & - & - & - & - & - & \overline{1} & - \\
\text { I } & 0.9 & 1.02 & 0.2 & 1 & 0.375 & 5 & 0.54 m_{\mathrm{e}} \\
\text { II } & 0.87 & 0.99 & 0.17 & 1 & 0.375 & 5 & 0.54 m_{\mathrm{e}}
\end{array}
\end{aligned}
$$

The parameters of the internal transition are those determined by optical absorption [7]. The two sets of numerical data are given in the table II. The fits are made supposing Dirac potential and allowed transitions.

We can make the following remark in view of the used procedure. The model adds the optical ionization cross section taking into account the band structure and the one due to the internal transition yielding to ionization. $P_{i}$ is just a numerical parameter of connection without physical meaning.

The part of the ionization cross section due to the internal transition include two successive processes :

$$
\mathrm{Cr}^{+2} \underset{\mathrm{I}}{\stackrel{h v}{\longrightarrow}}\left(\mathrm{Cr}^{+2}\right)^{*} \underset{\mathrm{II}}{\longrightarrow} \mathrm{Cr}^{+3}+\mathrm{e}_{\mathrm{BC}}^{-} \text {. }
$$

If we compare the DLOS results with optical absorption ones very close together, the process II seems very efficient in the charge space range of the Schottky diode. The electric field sweeps out the excited electron in the resonant state with the conduction band. This

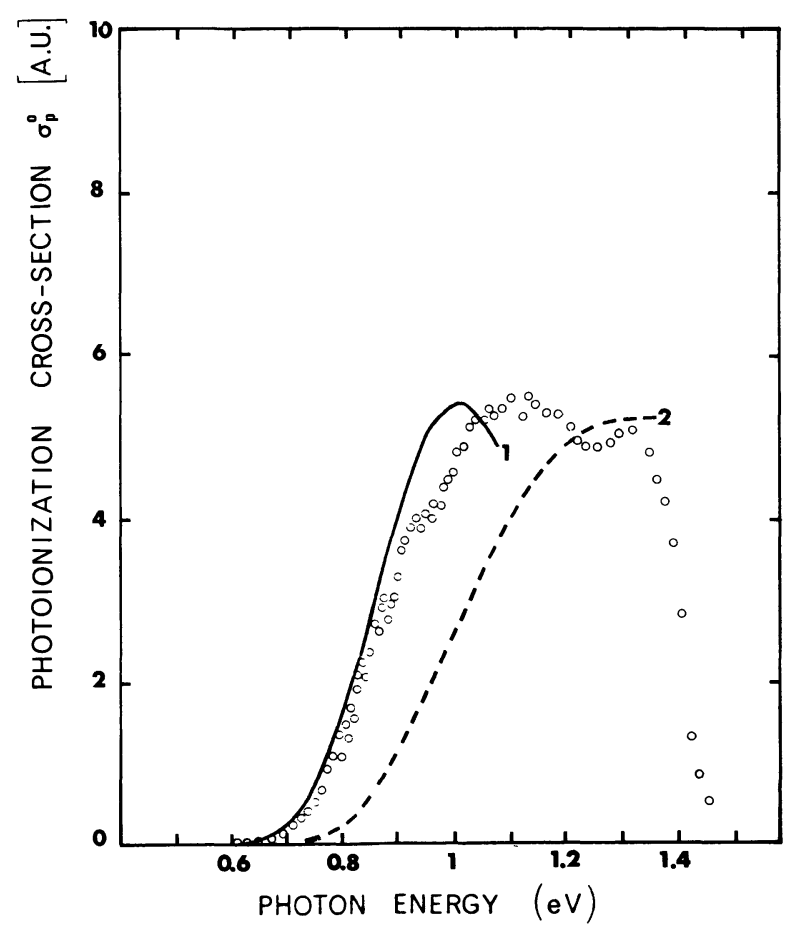

Fig. 4. - Photoionization cross section $\sigma_{\mathrm{p}}^{\circ}$ of HL1 at $320 \mathrm{~K}$. Experiment : OOO; theoretical fit with the same set of parameters as table III assuming a Coulomb potential instead of a Dirac one : 1 ; and forbidden transitions instead of permitted transitions : 2 . 


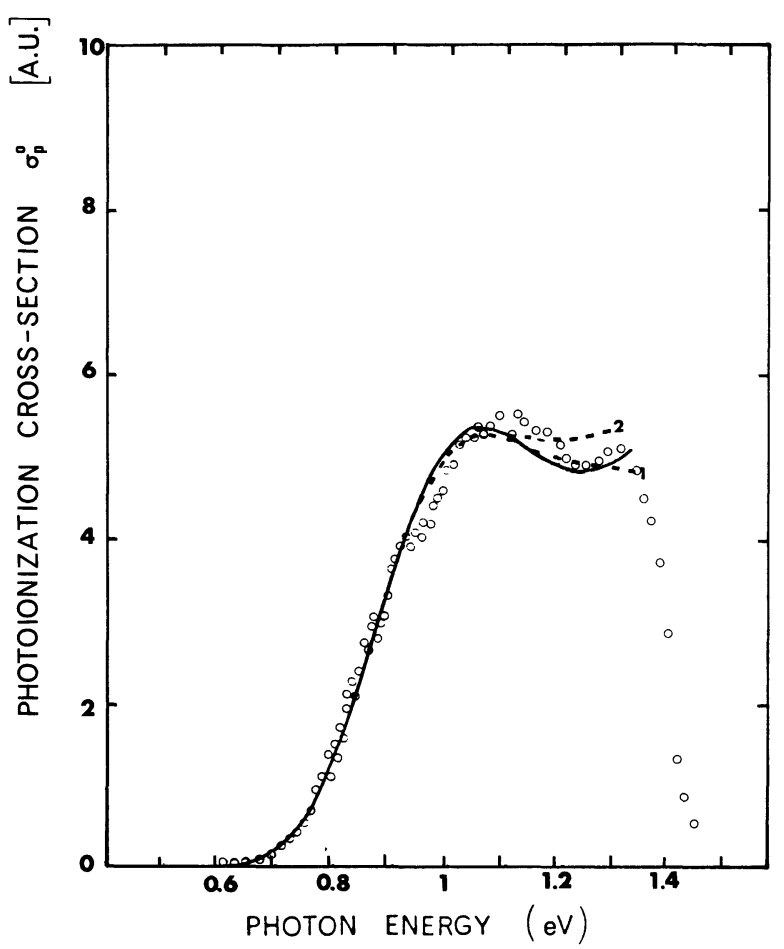

Fig. 5. - Photoionization cross section $\sigma_{\mathrm{p}}^{\mathrm{o}}$ of HL1 at $320 \mathrm{~K}$. Experiment : 000 ; theoretical fit with the same set of parameters as table III including transitions from the $\Gamma_{7}$ valence band. --.- : permitted transitions from $\Gamma_{7}$ : $1 P_{1,2}^{\prime}=P_{1,2} ; 2 P_{1,2}^{\prime}=1.3 P_{1,2} ;-$ : forbidden transitions from $\Gamma_{7}$.

process can not be put in evidence by EPR in bulk material, the ratio of $\mathrm{Cr}^{+3} / \mathrm{Cr}^{+2}$ under excitation staying very low.

b) $\sigma_{\mathrm{p}}^{\mathrm{o}}(320 \mathrm{~K})$. - The two theoretical fits corresponding to the two different values of $d_{\mathrm{FC}}$ used before (table III) are plotted in figure 2 for electronic transitions allowed and Dirac potential for the deep centre. Figure 4 shows for instance the fit I with forbidden transitions, and Coulomb potential. There appears also an increase of $\sigma_{\mathrm{p}}^{\mathrm{o}}$ for $h v>1.2 \mathrm{eV}$ probably due to the transition from the valence band $\Gamma_{7}(0.35 \mathrm{eV}$ below the valence band maximum at $\Gamma$ point [46]). Figure 5 shows tentatively a fit including this transition. This fit is only good if the latter is forbidden.

3. 2 PhotoluminesCENCE EXPERIMENTS (LOW TEMPERATURE MEASUREMENTS). - 3.2.1 Emission spectra. - a) Results. In all the semi-insulating and in the $\mathrm{p}$ type chromium doped GaAs samples (either Bridgman or Czochralski), we found a dominant broad band at $0.57 \mathrm{eV}$ under YAG laser excitation at $4 \mathrm{~K}$. Another weak broad band is peaking at $0.78 \mathrm{eV}$ in this type of material. Figure 6 shows these two bands in a typical semi-insulating sample doped with chromium. Figure 7 gives the temperature dependence of these two bands under YAG laser excitation. The $0.57 \mathrm{eV}$ band disappears with an activation energy of $80 \mathrm{meV}$ while the behaviour of the $0.78 \mathrm{eV}$ band as a function of temperature is much more complex and is

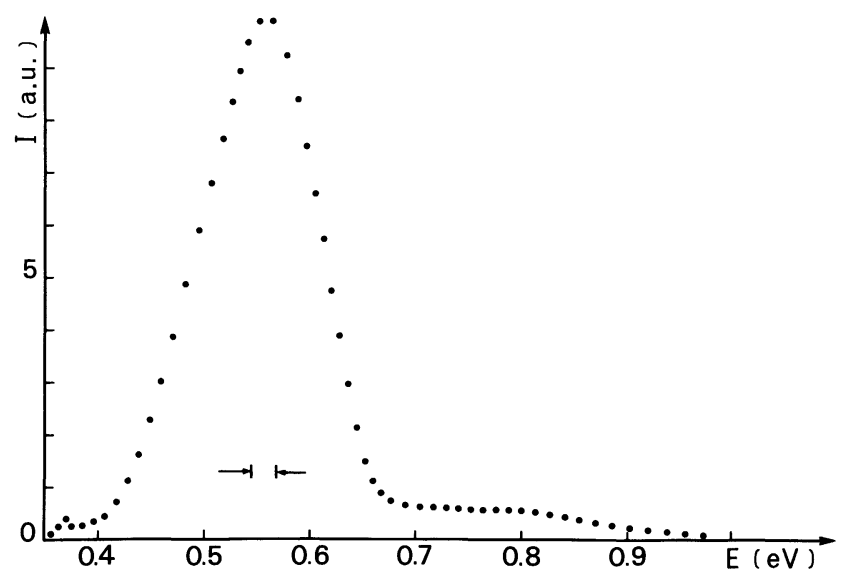

Fig. 6. - Luminescence spectrum of a semi-insulating chromium doped GaAs sample (RT 512) under YAG laser excitation at $4.5 \mathrm{~K}$.

exactly the same as the dependence observed for the $0.839 \mathrm{eV}$ line by $\mathrm{Yu}$ [47]. This $0.839 \mathrm{eV}$ zero phonon line typical of semi-insulating chromium doped samples under argon laser excitation, and which is now interpreted as a transition related to a chromium impurity nearest neighbour complex $[6,48]$ is not visible in our conditions of excitation. The $0.57 \mathrm{eV}$ band has been found not to be Gaussian [38].

In all the $n$ type chromium doped samples, an intense band peaking at $0.62 \mathrm{eV}$ is always present together with the common, but not understood, $1 \mathrm{eV}$ band (Fig. 8). Figures 9 and 10 give the temperature dependence of the intensity of the $0.62 \mathrm{eV}$ band and of its

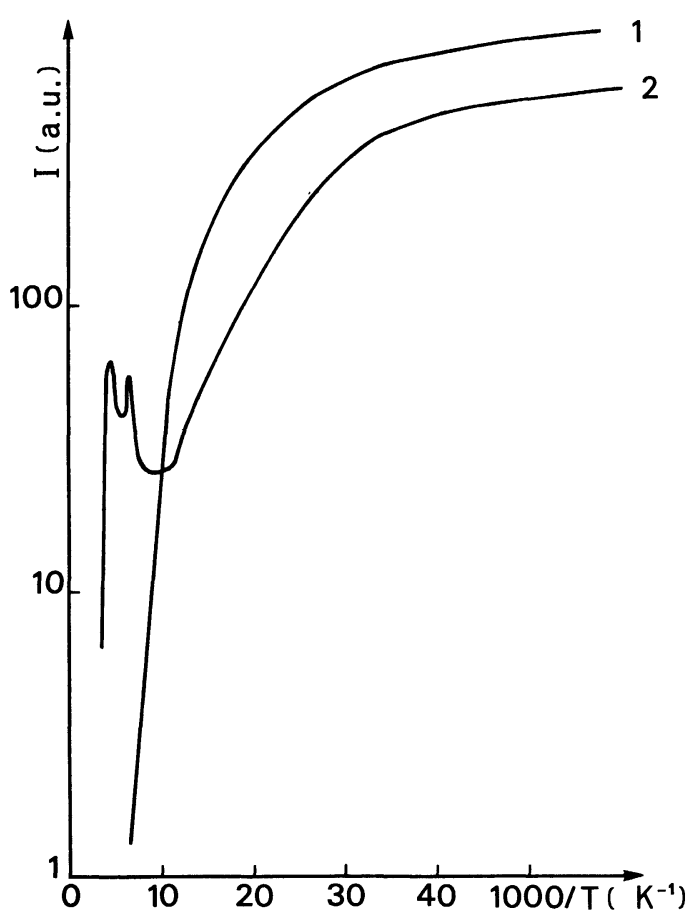

Fig. 7. - Temperature dependence of the $0.57 \mathrm{eV}$ (curve 1) and $0.78 \mathrm{eV}$ (curve 2) under YAG laser excitation in a semiinsulating material (RT 512). 


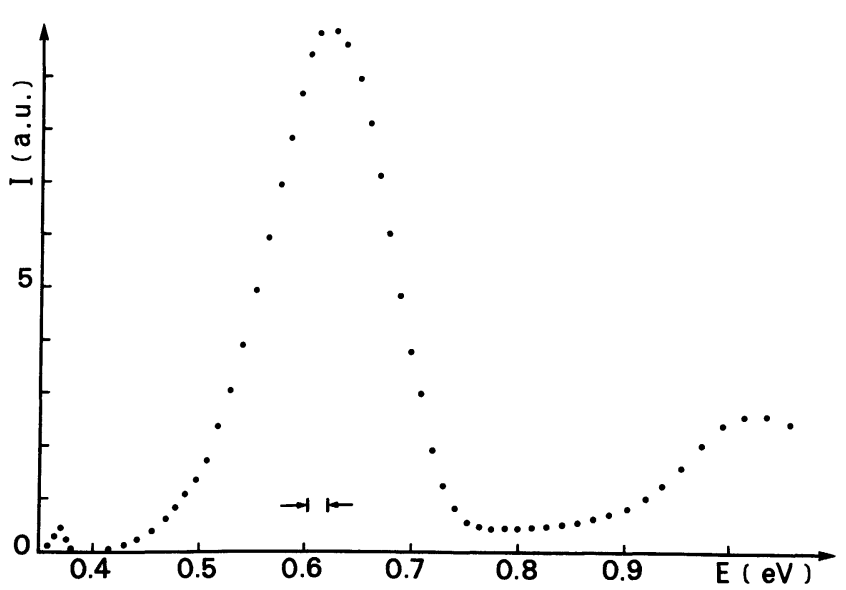

Fig. 8. - Luminescence spectrum of a $\mathbf{n}$ type chromium doped sample (RT 221) under YAG laser excitation at $4.5 \mathrm{~K}$.

half width respectively. We must point out that in most of the samples we analysed, we have detected a band at $0.37 \mathrm{eV}$ (Figs. 6 and 8) typical of the intracentre $\mathrm{Fe}^{2+}$ radiative transition $\left({ }^{5} \mathrm{~T}_{2} \rightarrow{ }^{5} \mathrm{E}\right)$. Its excitation mechanism under YAG excitation will be presented elsewhere [49].

So our results are in agreement with those of Deveaud et al. [38] namely that the $0.57 \mathrm{eV}$ and $0.62 \mathrm{eV}$ are typical of semi-insulating and $\mathbf{n}$ type chromium doped GaAs respectively. We have checked that these two bands are absent in undoped GaAs of $\mathbf{n}$ type (either Bridgman or Czochralski grown) and semi-

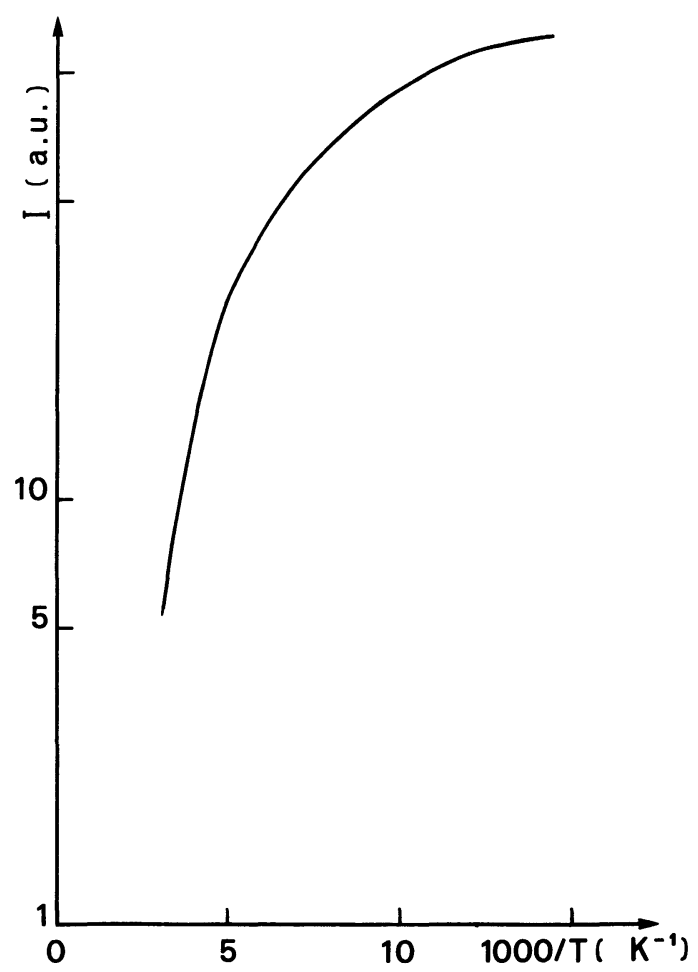

Fig. 9. - Temperature dependence of the $0.62 \mathrm{eV}$ band intensity under YAG laser excitation in an $\mathrm{n}$ Cr doped sample (RT 427 Q).

LE JOURNAL DE PHYSIQUe - T. 43, No 5, MaI 1982

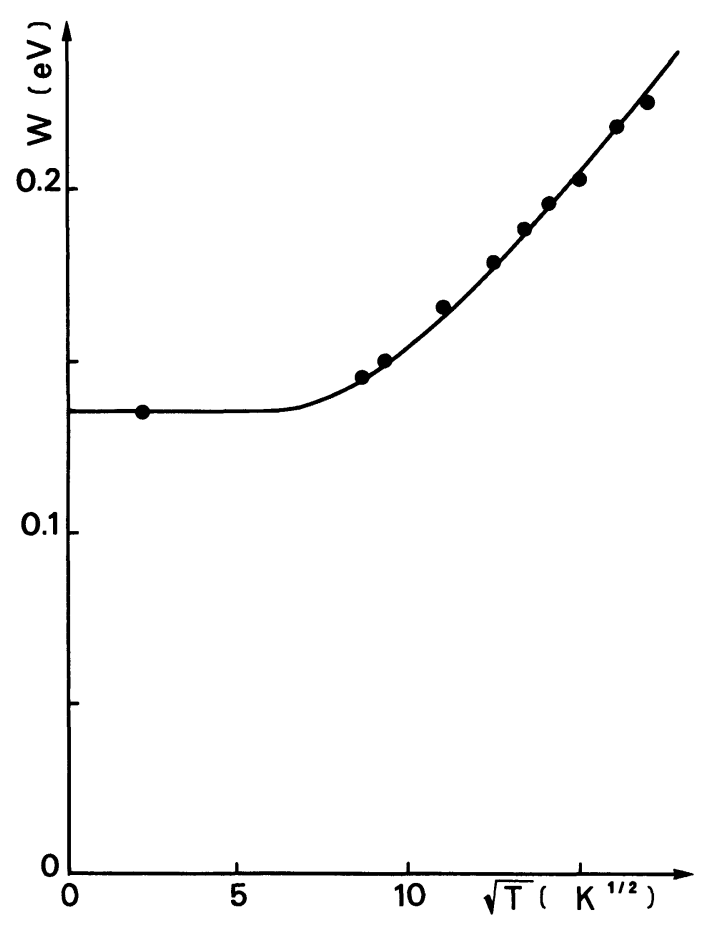

Fig. 10. - Temperature dependence of the $0.62 \mathrm{eV}$ band half width under YAG laser excitation in an $\mathrm{n} \mathrm{Cr}$ doped sample (RT 427 Q).

insulating GaAs obtained without chromium doping (either Bridgman grown sample with $\mathrm{Ga}_{2} \mathrm{O}_{3}$ added to the melt or undoped Czochralski grown material). So it appears as Deveaud et al. [38] concluded that these two bands are due to chromium.

b) Theoretical treatment. - For these two bands we have tried two classical fits involving either a gaussian band or a Pekarian band as follows :

$$
\begin{aligned}
I(h v) & =I_{0} \exp -\left(\frac{\left(h v-h v_{\mathrm{M}}\right)^{2}}{2 \sigma^{2}}\right) \\
h v_{\mathrm{M}} & =E_{0} \quad \text { (maximum of the emission) }
\end{aligned}
$$

with

$$
\sigma=\sigma_{0}\left(\operatorname{coth} \frac{\hbar \omega}{2 k T}\right)^{1 / 2}
$$

and

$$
\sigma_{0}=S^{1 / 2} \hbar \omega
$$

for a gaussian band.

We use generally the value of the half width :

$$
\begin{aligned}
& W(T)=2 \sigma(2 \ln 2)^{1 / 2} \\
& I(h v)=I_{0} \exp (-S) \frac{S\left(\frac{E_{\mathrm{T}}-E_{\mathrm{V}}-h v}{\hbar \omega}\right)}{\left(\frac{E_{\mathrm{T}}-E_{\mathrm{V}}-h v}{\hbar \omega}\right) !}
\end{aligned}
$$

for a Pekarian band 


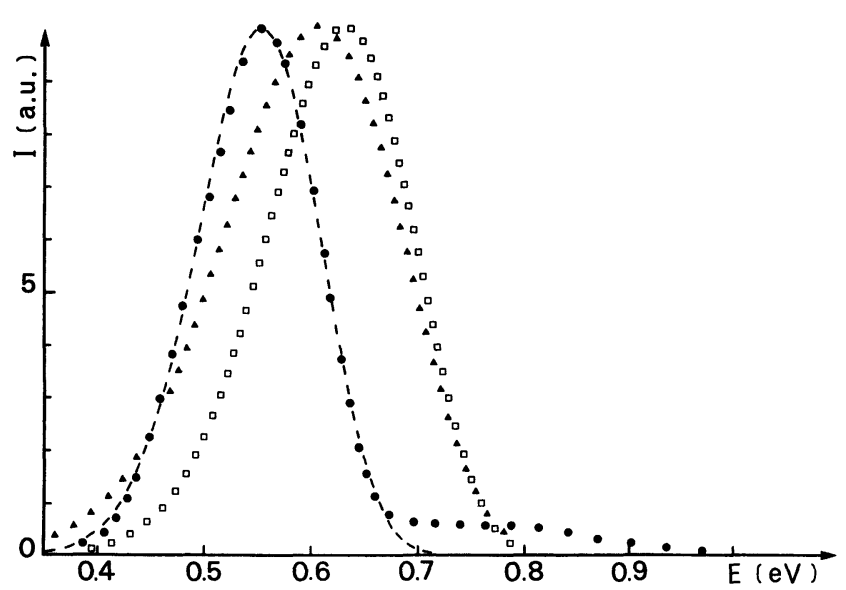

Fig. 11. -0.57 emission band observed in semi-insulating and $\mathrm{p}$ type $\mathrm{Cr}$ doped GaAs : curves $1(\Delta)$ and $2(\square)$ correspond to the parameters $\hbar \omega$ and $d_{\mathrm{FC}}$ following reference [42] and reference [45] respectively; curve $3(-)$ is the best fit obtained; curve $4(\bullet)$ : experimental points (see text and table IV).

In these expressions, the symbols have their usual meaning : $S$ being the Huang-Rhys coupling constant (mean number of emitted phonons), $\hbar \omega$ the energy of the phonon coupled to the level and $E_{\mathrm{T}}-E_{\mathrm{V}}$ the thermal energy of the level. The Frank Condon shift is $d_{\mathrm{FC}}=S \hbar \omega$.

a) Emission at $0.57 \mathrm{eV}$. - This band as observed by Deveaud et al. [38] is not symmetrical and can be fitted using a Pekarian form (Fig. 11). The set of parameters of the fit is given in table IV. We must point out that our best fit corresponds very well to the values found by Deveaud et al. [38].

$\beta)$ Emission at $0.62 \mathrm{eV}$. - This band is gaussian and at $4 \mathrm{~K}$ its maximum and half width are respectively $0.62 \mathrm{eV}$ and $135 \mathrm{meV}$ (Fig. 8).

A fit of the temperature dependence of $W$ (Fig. 10) following relation (3) yields the values of $W_{0}$ and $\hbar \omega$ and thus of $d_{\mathrm{FC}}$. We get the best fit (Fig. 12 and table V)

$$
\begin{aligned}
\hbar \omega & =18 \pm 2 \mathrm{meV} \\
S & =10.1 \\
d_{\mathrm{FC}} & =S \hbar \omega=180 \pm 20 \mathrm{meV} .
\end{aligned}
$$

The two theoretical 1 and 2 curves of figures 11 and 12 correspond to the set of parameters 1 and 2 (tables IV, V) used for the simulations I and II of $\sigma_{\mathrm{n}}^{\circ}$ and $\sigma_{\mathrm{p}}^{\mathrm{o}}$ (see section 4).

Table IV. - Parameters of the $0.57 \mathrm{eV}$ band theoretical curves given in figure 11 .

$\begin{array}{cccccc}\begin{array}{c}\text { Theoretical } \\ \text { curves }\end{array} & \begin{array}{c}E_{\mathrm{T}}-E_{\mathrm{V}} \\ (\mathrm{eV})\end{array} & \begin{array}{c}d_{\mathrm{FC}} \\ (\mathrm{eV})\end{array} & S & \begin{array}{c}\hbar \omega \\ (\mathrm{meV})\end{array} & \begin{array}{c}E_{0} \\ (\mathrm{meV})\end{array} \\ 1 & - & - & - & - & - \\ 2 & 0.790 & 0.200 & 5.7 & 35 & 590 \\ 3 \text { (fit) } & 0.790 & 0.170 & 6.1 & 28 & 620 \\ & 0.760 & 0.210 & 14.3 & 15 & 550\end{array}$

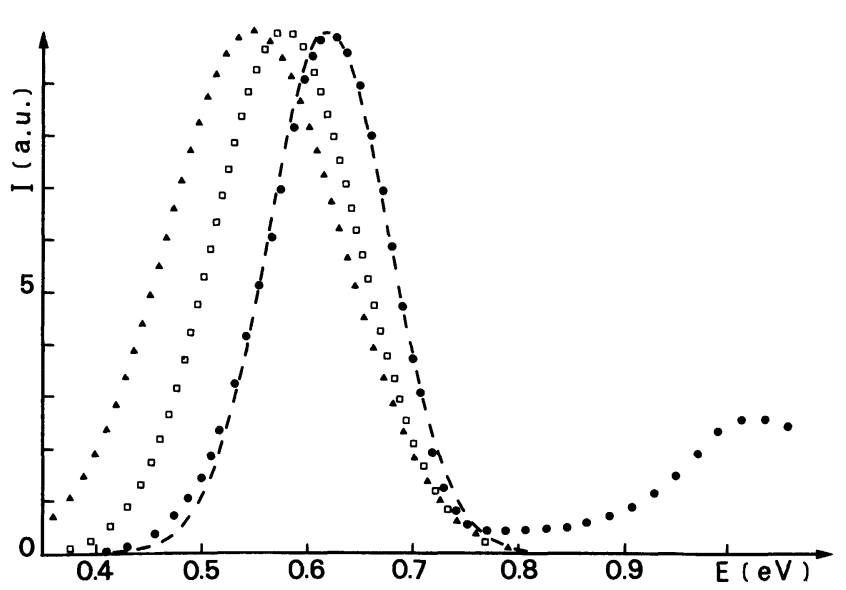

Fig. 12. -0.62 emission band observed in $\mathrm{n}$ type $\mathrm{Cr}$ doped GaAs : curves $1(\Delta)$ and $2(\square)$ correspond to the parameters $\hbar \omega$ and $d_{\mathrm{FC}}$ following reference [42] and reference [45] respectively ; curve $3(-)$ is the best fit obtained ; curve $4(\bullet)$ : experimental points (see text and table V).

\begin{tabular}{|c|c|c|c|c|c|}
\hline $\begin{array}{c}\text { Theoretical } \\
\text { curves }\end{array}$ & $\begin{array}{c}E_{\mathrm{C}}-E_{\mathrm{T}} \\
(\mathrm{eV})\end{array}$ & $\begin{array}{l}d_{\mathrm{FC}} \\
(\mathrm{eV})\end{array}$ & $S$ & $\begin{array}{c}\hbar \omega \\
(\mathrm{meV})\end{array}$ & $\begin{array}{c}E_{0} \\
(\mathrm{eV})\end{array}$ \\
\hline- & - & - & - & - & \\
\hline 1 & 0.75 & 0.20 & 5.7 & 35 & 0.5 \\
\hline 2 & 0.75 & 0.17 & 6.1 & 28 & 0. \\
\hline 3 (fit) & 0.8 & 0.18 & 10.1 & 18 & 0. \\
\hline
\end{tabular}

Table V. - Parameters of the $0.62 \mathrm{eV}$ band theoretical curves given in figure 12 .

3.2.2 Excitation spectra of luminescence (ESL). As far as radiative deep levels emitting in the visible and very near infrared part of the spectrum are concerned, photoluminescence excitation and quenching spectra measurements have proven to be a powerful means of investigating the optical cross sections down to the lowest temperatures [50,51].

In our case ESL measurements are much more difficult due to low radiative efficiencies and the lack of sensitivity of the available infrared detectors. Nevertheless, because of the depth of these two emission bands with respect to the band gap of GaAs, we have been able to measure for the first time their ESL at $4.5 \mathrm{~K}$ between $0.7 \mathrm{eV}$ and $1.3 \mathrm{eV}$ [40]. Our aim is then to correlate them with the shapes of the photoionization cross sections $\sigma_{\mathrm{p}}^{\mathrm{o}}$ and $\sigma_{\mathrm{n}}^{\mathrm{o}}$ of the HL1 level measured by DLOS and also the results of optical absorption measurements. If correlation is good, we can then attribute unambiguously these transitions to transfers between the $\left(\mathrm{Cr}^{3+}-\mathrm{Cr}^{2+}\right)$ level and the conduction and valence bands.

a) $0.57 \mathrm{eV}$ band. - The ESL of this band is given in figure 13. Only the energies below band gap have been considered to be typical of this luminescence band. With greater than band gap energy excitation, other bands appear in the PL spectrum and it is not possible to correlate the ESL with a simple band. The optical 


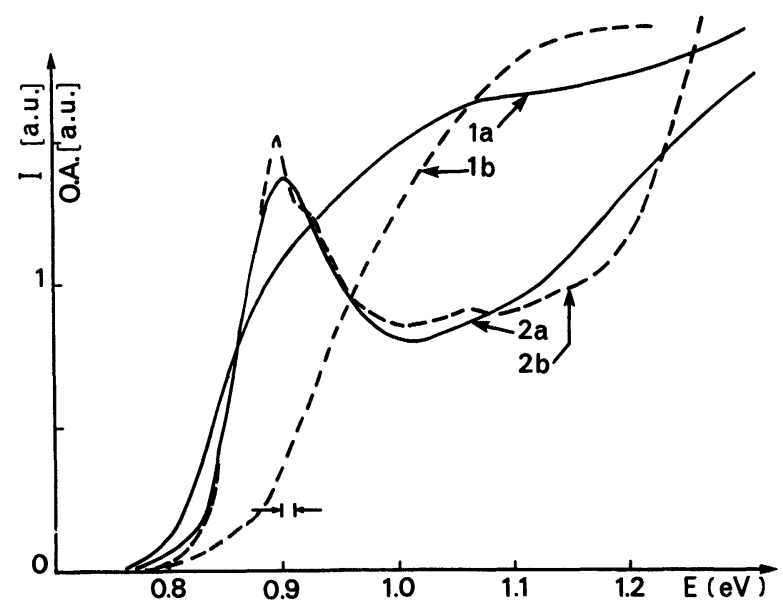

Fig. 13. - Excitation spectra of the $0.57 \mathrm{eV}$ band (curve 1a) and of the $0.62 \mathrm{eV}$ band (curve $2 a$ ) at $4.5 \mathrm{~K}$ on samples RT 512 and RT 221 respectively. -- : optical absorption spectra at 4.5 K of a semi-insulating $\mathrm{Cr}$ doped sample (curve $1 b$ ) and of $\mathrm{n}$ type $\mathrm{Cr}$ doped $\mathrm{GaAs}$ sample (curve $2 b$ ).

absorption of a SI Cr doped sample is plotted for comparison.

The optical photoionization cross section $\sigma_{\mathrm{p}}^{\circ}$ of $\mathrm{Cr}^{2+}$ at the same temperature will be analysed in section 4 (Fig. 14).

b) $0.62 \mathrm{eV}$ band. - Its ESL between $0.7 \mathrm{eV}$ and $1.3 \mathrm{eV}$ is given in figure 13 where the optical absorption of an $\mathrm{n}$ type $\mathrm{Cr}$ doped $\mathrm{GaAs}$ is plotted for comparison. The optical photoionization cross section $\sigma_{\mathrm{n}}^{0}$ of $\mathrm{Cr}^{2+}$ at the same temperature will be analysed in section 4 (Fig. 15).

4. Discussion. - The ESL and DLOS measurements are not carried out at the same temperature (4.5 K and about $300 \mathrm{~K}$ respectively). So, we are first going to discuss the use of DLOS technique to determine the origin of the emissions.

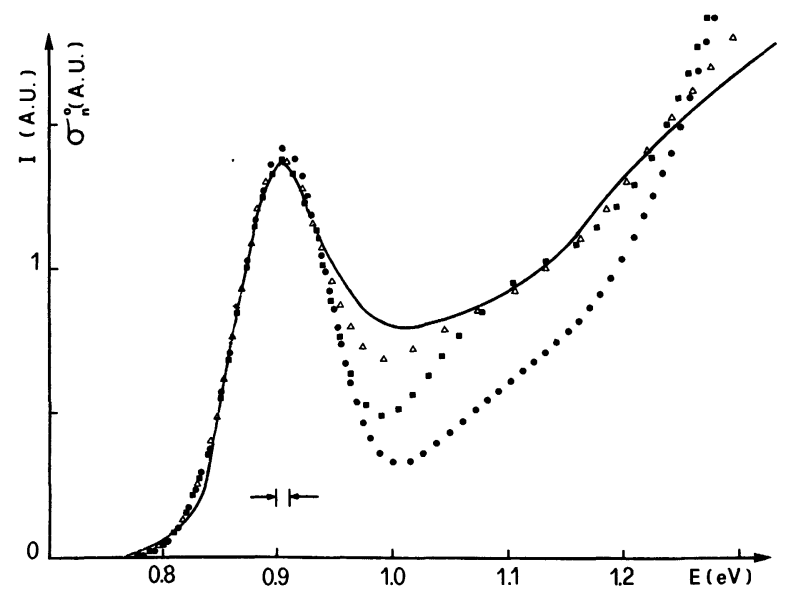

Fig. 14. - Excitation spectrum of the $0.62 \mathrm{eV}$ band (-) and theoretical simulations of the photoionization cross section $\sigma_{\mathrm{n}}^{\circ}$ at $4 \mathrm{~K}$ following numerical data of table VI ( $\bullet$ : simulation I, $\Delta$ : simulation II, $\square$ : simulation III).

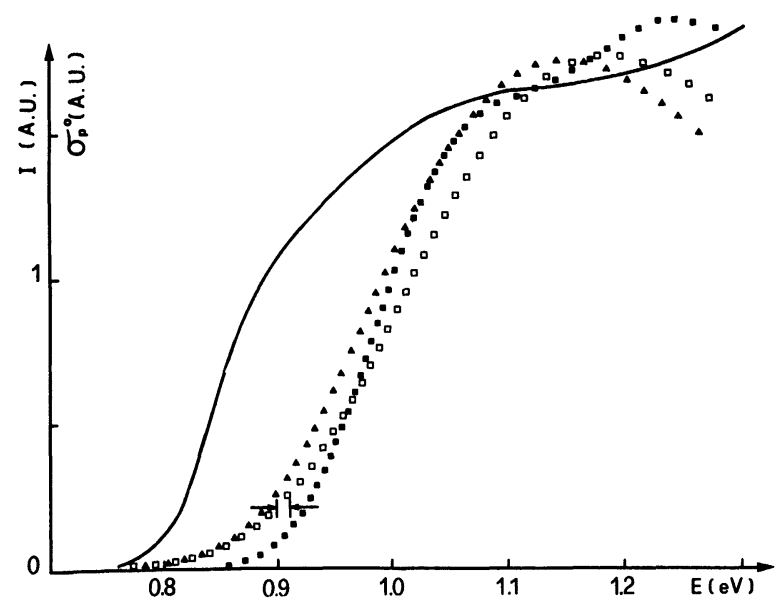

Fig. 15. - Excitation spectrum of the $0.57 \mathrm{eV}$ band $(-)$ and theoretical simulations of the photoionization cross section $\sigma_{\mathrm{p}}^{\circ}$ at $4 \mathrm{~K}$ following numerical data of table VII ( $\square$ : simulation I, $\boldsymbol{\Delta}$ : simulation II, $\square$ : simulation III).

4.1 Simulations OF THE OPTICAL PHOTOIONIZATION CROSS SECTIONS $\sigma_{\mathrm{n}}^{\circ}$ AND $\sigma_{\mathrm{p}}^{\circ}$ AT $4.5 \mathrm{~K}$. - In spite of the simplified theoretical treatment used to produce a limited number of significant parameters, it appears that this describes very faithfully the experimental results. The parameter values are able to vary to a certain extent without one fit being considered better than another. It is obvious that the model can only give a simplified representation of the experimental results and that a higher accuracy would be illusive and would not have physical meaning.

The comparison of $\sigma_{\mathrm{n}}^{\circ}$ and $\sigma_{\mathrm{p}}^{\circ}$ with the excitation spectra cannot be done directly, because the measurements are performed at very different temperatures. We proceed in the following way. We use the theoretical model to simulate $\sigma_{\mathrm{n}}^{\circ}$ and $\sigma_{\mathrm{p}}^{\circ}$ at $4 \mathrm{~K}$. Starting with the good fits I and II (tables II, III), we change only the parameters we know varying with the temperature and we adjust if necessary the transitions weights towards $\Gamma, \mathrm{L}, \mathrm{X}$ bands (simulations I and II, tables VI, VII). $E_{\Gamma}^{\circ}$ and $E_{1}^{\circ}$ are calculated from the formula giving

Table VI. - Numerical data used for the $\sigma_{\mathrm{n}}^{0}$ simulations at $4 \mathrm{~K}$ in figure 14.

\begin{tabular}{|c|c|c|c|c|c|c|c|c|c|}
\hline Simu- & $E_{i}^{\circ}$ & $\sigma_{i}$ & Norme & $/$ transi & tion & $\rightarrow \Gamma$ & & & \\
\hline I & 0.9 & $0.04 \mid$ & & 0.017 & & & & & \\
\hline II & 0.9 & 0.04 & & 0.011 & & & & & \\
\hline III & 0.9 & $0.04 \mid$ & & 0.011 & & & & & \\
\hline & $\begin{array}{c}E_{\Gamma}^{\circ} \\
(\mathrm{eV})\end{array}$ & $\mid \begin{array}{l}d_{\mathrm{FC}} \\
(\mathrm{eV})\end{array}$ & $\begin{array}{c}\Delta E_{\Gamma \mathrm{L}}^{\mathrm{o}} \\
(\mathrm{eV})\end{array}$ & $\begin{array}{c}\Delta E_{\Gamma \mathrm{x}}^{\mathbf{0}} \\
(\mathrm{eV})\end{array}$ & $\left|P_{\Gamma}\right|$ & $P_{\mathrm{L}}$ & $P_{\mathbf{x}}$ & $\begin{array}{c}\alpha^{-1} \\
(\AA)\end{array}$ & $\begin{array}{c}\hbar \omega \\
(\mathrm{meV})\end{array}$ \\
\hline I & 0.95 & 0.2 & 0.29 & 0.46 & 1 & 0.25 & 0.1 & 5 & 35 \\
\hline II & 0.92 & 0.17 & 0.29 & 0.46 & 1 & 0.079 & 0.05 & 5 & 28 \\
\hline III & 0.98 & 0.18 & 0.29 & 0.46 & 1 & 0.13 & 0.053 & 5 & 18 \\
\hline
\end{tabular}


Table VII. - Numerical data used for the $\sigma_{\mathrm{p}}^{\mathrm{o}}$ simulations at $4 \mathrm{~K}$ in figure 15.

$\begin{array}{cccccccc}\begin{array}{c}\text { Simu- } \\ \text { lation }\end{array} & \begin{array}{c}E_{1}^{\circ} \\ (\mathrm{eV})\end{array} & \begin{array}{c}E_{2}^{\mathrm{o}} \\ (\mathrm{eV})\end{array} & \begin{array}{c}d_{\mathrm{FC}} \\ (\mathrm{eV})\end{array} & P_{1} & P_{2} & \begin{array}{c}\alpha^{-1} \\ (\AA)\end{array} & \begin{array}{c}\hbar \omega \\ (\mathrm{meV})\end{array} \\ - & - & - & - & - & - & - & - \\ \text { I } & 0.99 & 1.11 & 0.2 & 1 & 0.375 & 5 & 35 \\ \text { II } & 0.96 & 1.08 & 0.17 & 1 & 0.375 & 5 & 28 \\ \text { III } & 0.98 & 1.18 & 0.21 & 1 & 0.375 & 5 & 15\end{array}$

the variation of $E_{\mathrm{C}}-E_{\mathrm{T}}$ with temperature after [20] and

$$
\begin{aligned}
& E_{\Gamma}^{\mathrm{o}}=E_{\mathrm{C}}-E_{\mathrm{T}}+d_{\mathrm{FC}} \\
& E_{1}^{\mathrm{o}}=E_{\mathrm{T}}-E_{\mathrm{V}}+d_{\mathrm{FC}}
\end{aligned}
$$

$\Delta E_{\Gamma \mathrm{X}}$ and $\Delta E_{\Gamma \mathrm{L}}$ at $4 \mathrm{~K}$ are given in [43]; $E_{1}^{\circ}-E_{2}^{\circ}=120 \mathrm{meV}$ [9]. The simulation III (tables VI, VII) corresponds to the set of parameters giving the best accordance with the emission results (fit 3, tables IV, V). The theoretical simulations are plotted on figures 14 and 15 for $\sigma_{\mathrm{n}}^{\circ}$ and $\sigma_{\mathrm{p}}^{\circ}$ respectively.

The comparison of $\sigma_{\mathrm{n}}^{\mathrm{o}}$ and $\sigma_{\mathrm{p}}^{\mathrm{o}}$ deduced from the model with the ESL and absorption measurements at $4 \mathrm{~K}$ (Figs. 13, 14, 15) allows us to maintain the correlation between : (i) $\sigma_{\mathrm{n}}^{\circ}$, the ESL of the emission at $0.62 \mathrm{eV}$ - and the optical absorption in the $n$ material; (ii) $\sigma_{\mathrm{p}}^{\circ}$, the ESL of the emission at $0.57 \mathrm{eV}$ and the optical absorption in the semi-insulating or $p$ type materials in which the chromium is in majority in the state $\mathrm{Cr}^{+3}$. This point is also confirmed by the fact that the quenching spectra of the $0.57 \mathrm{eV}$ band and of the EPR signal associated with $\mathrm{Cr}^{+3}$ are rather similar [15].

On the other hand, the limitation of the model appears if we use directly the parameters $\hbar \omega$ and $d_{\mathrm{FC}}$ used for the $\sigma_{\mathrm{n}}^{\mathrm{o}}$ and $\sigma_{\mathrm{p}}^{\mathrm{o}}$ simulation, to anticipate the emission shapes and positions.

The choice of the parameters $\hbar \omega$ and $d_{\mathrm{FC}}$ is very important in order to compare the theoretical and experimental emission spectra. In the model the emission energy is $E_{\mathrm{e}}=E^{\circ}-2 d_{\mathrm{FC}}$, the half width value $W=2(2 \ln 2)^{1 / 2}\left(\hbar \omega d_{\mathrm{FC}}\right)^{1 / 2}$ for the gaussian (about the same for the two emissions). The agreement between the experimental and theoretical results concerning the emissions summarized in tables IV and $\mathrm{V}$ and plotted in figures 11 and 12 is rather good considering the very crude approximations made (linear coupling, harmonic approximation).

4.2 Concluding Remarks. - Our DLOS experiments performed on $\mathbf{n}$ and $\mathrm{p}$ type chromium doped GaAs have led to observations consistent with the thermal properties of the HL1 trap and reinforce the conclusion that chromium isolated on $\mathrm{Ga}$ site gives only one level in the gap related to the single acceptor state $\left(\mathrm{Cr}^{2+}\right)$, the double acceptor level being degenerated with the conduction band [10,42]. Moreover, all our measurements do not permit us to put in evidence the $\left(\mathrm{Cr}^{4+}-\mathrm{Cr}^{3+}\right)$ level $[17,33]$. This can be explained by the following reasons :

i) all luminescence measurements concern $\mathrm{n}$ and semi-insulating of type $n$ and $p$ materials and not a real $\mathrm{p}$ type one at low temperature;

ii) in $p$ LPE layer, the photoionization cross sections are measured at a temperature where the hole thermal emission rate of this level (if it exists) is too high. But the DLTS data give in the range $4 \mathrm{~K}-350 \mathrm{~K}$ only the HL18, HL5, HL2 and HL1 traps [20]. HL2 and HL5 are known to be specific levels of LPE materials [18]. HL18 is unknown but we have checked it cannot be connected with the $\left(\mathrm{Cr}^{4+}-\mathrm{Cr}^{3+}\right)$ level. The analysis of the DLOS signals at temperature higher and lower than the HL18 DLTS peak shows that the disappearance of the signal due to HL18 involve no change to the other responses therefore the signal due to HL1 is the same.

The determination of the optical photoionization cross sections $\sigma_{\mathrm{n}}^{\circ}$ and $\sigma_{\mathrm{p}}^{\circ}$ of the $\left(\mathrm{Cr}^{3+}-\mathrm{Cr}^{2+}\right)$ level unambiguously and in a large range of energy by the DLOS technique have proved to be very important. On the one hand, their knowledge permits the analysis of semi-insulating bulk materials by optical absorption in a routine way after calibrations [34]. On the other hand it appears that careful comparisons between the excitation spectra of some unknown deep centre luminescences with photoionization spectra can lead to identification of radiative levels. The 0.62 and $0.57 \mathrm{eV}$ bands have thus been shown to be related to the single acceptor level of chromium in gallium site and due to the following processes :

$$
\begin{aligned}
& \mathrm{Cr}^{3+}+\mathrm{e}_{\mathrm{CB}}^{-} \rightarrow \mathrm{Cr}^{2+}+h v(0.62 \mathrm{eV}) \\
& \mathrm{Cr}^{2+}+\mathrm{h}_{\mathrm{VB}}^{+} \rightarrow \mathrm{Cr}^{3+}+h v(0.57 \mathrm{eV}) .
\end{aligned}
$$

Acknowledgments. - We wish to thank Dr G. Poiblaud (RTC Caen) for supplying most of the studied crystals and also Dr G. Jacob and J. P. Farge (LEP), Dr L. Eaves (Nottingham University), Dr E. M. Swiggard (NRL), Dr D. W. Woodard (Cornell University) for the gift of some samples and Dr B. Clerjaud for helpful discussions. We also express special thanks to G. M. Martin for critical discussions of this manuscript. This work was partially supported by DRET under contract 79.047 .

\section{References}

[1] Zucca, R., Welch, B. M., Asbeck, P. M., Eden, R. C., Long, S. I., Proc. of the 1st Conf. on Semi-Ins. III-V Material Conf., Nottingham, 1980 (Shiva Pub. Ed) p. 335.
[2] Koschel, W. H., Bishop, S. G., McCombe, B. D., Solid State Commun. 19 (1976) 521.

[3] Stocker, H. J., SCHMidT, M. J., J. Appl. Phys. 47 (1976) 2450. 
[4] Lightowlers, E. C., Penchina, C. M., J. Phys. CSolid St. Physics 11 (1978) L-405.

[5] Deveaud, B., Favennec, P. N., Solid State Commun. 24 (1978) 473.

[6] Picoli, G., Deveaud, B., Galland, D., J. Physique 42 (1981) 133.

[7] Bors, D., J. Physique Colloq. 35 (1974) C3-241.

[8] Ippolitova, G. K., Omelyanovski, E. M., Pervova, L. Y., Sov. Phys. Semicond. 9 (1976) 864.

[9] Martinez, G., Hennel, A. M., Szuskiewicz, W., Balkanski, M., Clerjaud, B., Phys. Rev. B 23 (1981) 3920.

[10] Hennel, A. M., Szuskiewicz, W., Balkanski, M. Martinez, G., Clerjaud, B., Phys. Rev. B 23 (1981) 3933.

[11] Martin, G. M., VerheiJke, M. L., Jansen, J. A., Poiblaud, G., J. Appl. Phys. 50 (1979) 467.

[12] Kaufmann, U., Schneider, J., Solid State Commun. 20 (1976) 143.

[13] Krebs, J. J., Stauss, G. H., Phys. Rev. B 16 (1976) 971.

[14] Stauss, G. H., Krebs, J. J., Lee, S. H., Swiggard, E. M., J. Appl. Phys. 50 (1979) 6251.

[15] Krebs, J. J., Stauss, G. H., Phys. Rev. B 15 (1977) 17.

[16] Krebs, J. J., Stauss, G. H., Phys. Rev. B 20 (1979) 795.

[17] Stauss, G. H., Krebs, J. J., Lee, S. H., Swiggard, E. M., Phys. Rev. B 22 (1980) 3141.

[18] LaNG, D. V., Logan, R. A., J. Electron. Mater. 4 (1975) 1053.

[19] Mitonneau, A., Mircea, A., Martin, G. M., Pons, D., Revue Phys. Appl. 14 (1979) 853.

[20] Martin, G. M., Mitonneau, A., Pons, D., Mircea, A., Woodard, D. W., J. Phys. C (1980) 3855.

[21] Jesper, T., Hamilton, B., Peaker, A. R., Proc. of the 1st Conf. on Semi-Ins. III-V Material Conf., Nottingham, 1980 (Shiva Publ. Ed.) p. 233.

[22] Szawelska, H. R., Allen, J. W., J. Phys. C 12 (1979) 3359.

[23] White, A. M., Porteous, P., Dean, P. J., J. Electron. Mat. 5 (1976) 91.

[24] Vasudev, P. K., Bube, R. H., Solid State Electron. 21 (1978) 1095.

[25] Martin, G., Bois, D., Top Conf. on Charact. Techn., Seattle (1978) Proc. in volume 78.3 of the Electrochem. Soc., p. 32

[26] Hurtes, C., Boulou, M., Mitonneau, A., Bois, D., Appl. Phys. Lett. 32 (1978) 821.

[27] Deveaud, B., Toulouse, B., Proc. of the 1st Conf. on Semi-Ins. III-V Material Conf., Nottingham, 1980 (Shiva Publ. Ed.) p. 241.
[28] White, A. M., Dean, P. J., Porteous, P., J. Appl. Phys. 47 (1976) 3230.

[29] Lin, A. L., Bube, R. H., J. Appl. Phys. 47 (1976) 1859.

[30] Lin, A. L., Omelianovski, E., Bube, R. H., J. Appl. Phys. 47 (1976) 1852.

[31] Look, D. C., Solid State Commun. 24 (1977) 825.

[32] Brozel, M. R., Butler, J., Newman, R. C., RitSon, A., Stirland, D. J., Whitehead, C., J. Phys. C 11 (1978) 1857.

[33] Kaufmann, U., Schneider, J., Appl. Phys. Lett. 36 (1980) 747

[34] Martin, G. M., Jacob, G., Poiblaud, G., GoltZENE, A., SCHWAB, C., Proc. of the 11th ICDRES (Oiso, 1980) to be published in Inst. Phys. Conf. Ser.

[35] Chantre, A., Vincent, G., Bois, D., Phys. Rev. B 23 (1981) 5335.

[36] Chantre, A., Bois, D., Proc. 15th Int. Conf. Phys. of Semicond. (Kyoto 1980), J. Phys. Soc. Japan 49, Suppl. A (1980) 247.

[37] Bois, D., Chantre, A., Revue Phys. Appl. 15 (1980) 631.

[38] Deveaud, B., Hennel, A. M., Szuszkiewicz, W., Picoli, G., Martinez, G., Revue Phys. Appl. 15 (1980) 671 .

[39] White, A. M., Krebs, J. J., Stauss, G. H., J. Appl. Phys. 51 (1980) 419.

[40] Leyral, P., Litty, F., Loualiche, S., Nouailhat, A., Guillot, G., Solid State Commun. 38 (1981) 333.

[41] Chantre, A., Ph. D Thesis, Grenoble 1979 (unpublished).

[42] Hennel, A. M., Szuszkiewicz, W., Martinez, G., Clerjaud, B., Revue Phys. Appl. 15 (1980) 697.

[43] Aspnes, D. E., Phys. Rev. B 14 (1976) 5331.

[44] Makram-Ebeid, S., Appl. Phys. Lett. 37 (1980) 464.

[45] Makram-Ebeid, S., Lannoo, M., to be published in J. Phys. C.

[46] Chadi, D. J., Phys. Rev. 16B (1977) 790.

[47] YU, P. W., Solid State Commun. 32 (1979) 1111.

[48] Picoli, G., Deveaud, B., Galland, D., Proc. of the 1st Conf. on Semi-Ins. III-V Material Conf., Nottingham, 1980 (Shiva Publ. Ed.) p. 254.

[49] Leyral, P., Litty, F., Nouailhat, A., Gulllot, G., to be published.

[50] Monemar, B., Samuelson, L., Phys. Rev. B 18 (1978) 809.

[51] Samuelson, L., Monemar, B., Phys. Rev. B 18 (1978) 830. 